\title{
Ultrasonographic Assessment of Soft Tissues in Patients With Acromegaly
}

\author{
Mustafa KOÇAK, ${ }^{1}$ Nadim CIVAN, ${ }^{1}$ Murat KARKUCAK,, 2 Erhan ÇAPKIN, ${ }^{2}$ Melek GARİPOĞLU, ${ }^{2}$ \\ İpek CAN, ${ }^{2}$ Adem KARACA, ${ }^{3}$ Mustafa TAŞDELEN,${ }^{1}$ Ahmet $\mathrm{AYAR}^{4}$ \\ ${ }^{1}$ Department of Endocrinology and Metabolism, Medical Faculty of Karadeniz Technical University, Trabzon, Turkey \\ ${ }^{2}$ Department of Physical Medicine and Rehabilitation, Medical Faculty of Karadeniz Technical University, Trabzon, Turkey \\ ${ }^{3}$ Department of Physical Medicine and Rehabilitation, Medical Faculty of Erzincan University, Erzincan, Turkey \\ ${ }^{4}$ Department of Physiology, Medical Faculty of Karadeniz Technical University, Trabzon, Turkey
}

\begin{abstract}
Objectives: This study aims to investigate ultrasound examination findings of cartilage, tendon and nerve structures in patients with acromegaly and assess whether imaging findings have any association with the clinical and laboratory features of the patients.

Patients and methods: The study included 38 diagnosed acromegaly patients (18 males, 20 females; mean age $45.6 \pm 10.4$ years; range 28 to 63 years) and 21 control subjects ( 8 males, 13 females; mean age; $43.1 \pm 7.4$ years; range 29 to 58 years) similar for age, sex and body mass index. Patients' clinical characteristics and laboratory parameters were recorded. The cross sectional area of median nerve, flexor pollicis longus and Achilles tendon, and humeral cartilage thickness were bilaterally assessed by ultrasound.

Results: Arthralgia was present in 13 patients (34.9\%) and 11 (28.9\%) had paresthesia in the hands. Thickness of humeral cartilage and the cross sectional area of median nerve, flexor pollicis longus tendon and Achilles tendon was significantly higher in acromegaly patients compared with controls $(p<0.001)$. While measurements performed with ultrasound were correlated among themselves, no significant correlation was present between ultrasound measurements and growth hormone and insulin-like growth factor-1. When acromegaly patients were analyzed as active ( $\mathrm{n}=22$ ) and inactive $(n=16)$, no significant difference was determined in the parameters with the exception of median nerve measurements.

Conclusion: Ultrasound examination revealed significantly different cartilage, tendon and nerve parameters in acromegaly patients compared to the control group. Median nerve cross sectional area was significantly greater in active patients compared to inactive patients.

Keywords: Acromegaly; soft tissue structures; ultrasound.
\end{abstract}

Acromegaly is a clinical syndrome resulting from excessive production of growth hormone $(\mathrm{GH})$. Its onset is stealthy and gradual whereby the clinical features are associated with the hormonal effects of $\mathrm{GH}$ and insulin-like growth factor-1 (IGF-1) on bone, cartilage and connective tissues. ${ }^{1}$

In the early period, arthralgia is seen in $70 \%$ of acromegaly patients, commonly involving the hip, knee, ankle and wrist joints. ${ }^{2,3}$ Pain generally occurs due to the stimulating effect of GH and IGF-1 on cartilage and bone. ${ }^{4}$ Peripheral nerve problems are also common among acromegaly patients and ensue secondary to either neural growth itself or external soft tissue/bony compression..$^{5,6}$

On the other hand, the imaging technique of choice for monitoring soft tissue changes in acromegaly is yet unclear. Ultrasound (US) has been used in numerous studies as a handy, cost-effective and non-invasive technique in the diagnosis and management of various articular and soft tissue pathologies. ${ }^{7-9}$ To the best knowledge of the authors, there are a few studies which have reported joint cartilage thickening in acromegaly patients. ${ }^{10-12}$ 
The time being passed from the published studies, their relatively small sample size $e^{10,11}$ and widening of US use in musculoskelatal evaluation lead us to re-examine the topic, and highlight the availability and ease of use of this method for detection of soft tissue involvement in acromegaly.

Hence, in this study, we aimed to investigate US examination findings of cartilage, tendon and nerve structures in patients with acromegaly and assess whether imaging findings have any association with the clinical and laboratory features of the patients.

\section{PATIENTS AND METHODS}

The study was performed in Medical Faculty of Karadeniz Technical University, Trabzon, Turkey, between December 2012 and February 2013. Thirty-eight acromegaly patients (18 males, 20 females; mean age $45.6 \pm 10.4$ years; range 28 to 63 years) and 21 control subjects (8 males, 13 females, mean age $43.1 \pm 7.4$ years; range 29 to 58 years) similar for age, sex and body mass index were enrolled. Twentytwo (57\%) acromegaly patients were receiving medical treatment (octreotide and/or lanreotide). The diagnosis of acromegaly was based on established criteria. ${ }^{13}$ Active acromegaly was diagnosed by the presence of the following findings: typical clinical signs and symptoms, random $\mathrm{GH}>1 \mathrm{ng} / \mathrm{mL}, \mathrm{GH} \geq 0.4 \mathrm{ng} / \mathrm{mL}$ after ingestion of $75 \mathrm{~g}$ glucose and elevated ageadjusted IGF-1 levels above normal range for age and sex..$^{13,14}$ Estimated disease duration was determined by assessment of patients' past photographs and the onset of clinical symptoms/ findings of acromegaly. Subjects with a history of other associated systemic inflammatory diseases or knee trauma were excluded.

This study was conducted in accordance with the guidelines in the Helsinki Declaration, and the local ethics committee approved the study protocol. All subjects were informed about the study procedure and their written informed consents were obtained.

All subjects were examined with a commercial, real-time equipment (Esaote, Mylab 60, Genova, Italy) using a 6-18 $\mathrm{MHz}$ linear array transducer following a standardized scanning method. The same physician, experienced in musculoskeletal US, who was blinded to patients' data performed all the ultrasonographic measurements involving distal humeral cartilage thickness, cross sectional area (CSA) for flexor pollicis longus (thenar region), Achilles tendon (at the level of the medial malleolus), and median nerve (at carpal tunnel entrance) (Figures 1a-d). To increase the accuracy of measurements, all images were also evaluated by another researcher experienced in US for more than 5 years.

Blood samples were collected in the morning between 08:00 and 09:00 AM after overnight fasting. Chemiluminescent immunometric assay (Immulite 2000 DPC, Diagnostic Products, Los Angeles, CA, USA) was used to measure serum GH and IGF-1 levels. Normal level for serum GH was $5 \mathrm{ng} / \mathrm{mL}$. Normal range for IGF-1 was ageadjusted but not sex-adjusted. ${ }^{15}$

\section{Statistical analysis}

Normal distribution was tested using Kolmogorov-Smirnov test. Data are expressed as mean \pm standard deviation or percentage values. Group comparisons were performed by Student t, Mann-Whitney U and Chi-square tests, where appropriate. Correlation analyses were done using Pearson and Spearman coefficients. Statistical significance was set at $p<0.05$. SPSS for Windows version 13.0 software program (SPSS, Inc., Chicago, IL, USA) was used for all the statistical analyses.

\section{RESULTS}

Baseline characteristics of patients and control subjects are listed in Table 1. The two groups were similar with respect to age, sex and body mass index. Arthralgia was present in 13 patients (34.9\%) and paresthesia was present in the hands of 11 patients (28.9\%). Disease duration of the study group ranged from $0.5-30$ years (mean $6.2 \pm 6.4$ years).

Median nerve, flexor pollicis longus and Achilles tendon CSA, and humeral cartilage thickness values are summarized in Table 2 . All parameters were significantly higher in acromegaly patients compared to control subjects $(p<0.001)$. Median nerve measurements were 

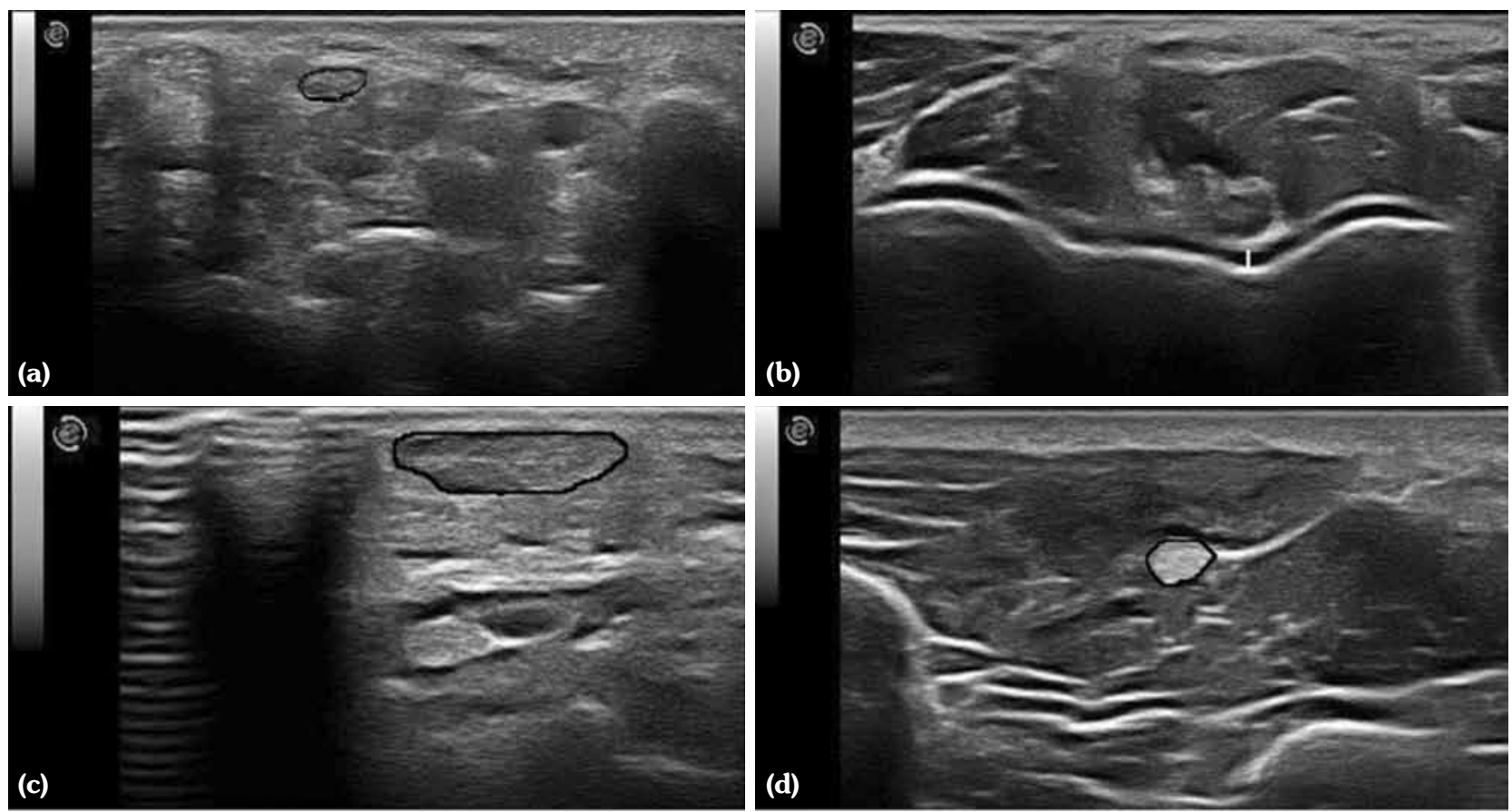

Figure 1. (a) Median nerve, (b) elbow cartilage, (c) Achilles tendon, (d) flexor pollicis longus.

similar between acromegaly subjects, with and without paresthesia symptoms ( $p>0.05)$. When active $(n=22)$ and inactive $(n=16)$ acromegaly patients were compared, only median nerve CSA values were greater in the former group bilaterally $(p<0.05$, Table 3$)$. Although US measurements were correlated among each other, they did not show any significant correlation with GH/IGF-I levels or disease/ treatment duration $(p>0.05)$.

\section{DISCUSSION}

In this study, we examined some soft tissue changes of acromegaly patients using US. Cartilage, tendon and nerve parameters were shown to be significantly different in the acromegaly group. Also, median nerve CSA values seemed to be greater in the active group.

Symptoms or signs related to articular involvement usually present at diagnosis in the

Table 1. Clinical characteristics of acromegaly patients compared with control group

\begin{tabular}{|c|c|c|c|c|c|c|c|}
\hline & \multicolumn{3}{|c|}{ Acromegaly group $(n=38)$} & \multicolumn{3}{|c|}{ Control group $(\mathrm{n}=21)$} & \multirow[b]{2}{*}{$p$} \\
\hline & $\mathrm{n}$ & $\%$ & Mean \pm SD & $\mathrm{n}$ & $\%$ & Mean \pm SD & \\
\hline Age (years) & & & $45.6 \pm 10.4$ & & & $43.1 \pm 7.4$ & 0.293 \\
\hline Sex & & & & & & & 0.680 \\
\hline $\begin{array}{l}\text { Female } \\
\text { Male }\end{array}$ & $\begin{array}{l}20 \\
18\end{array}$ & & & $\begin{array}{c}13 \\
8\end{array}$ & & & \\
\hline Body mass index $\left(\mathrm{kg} / \mathrm{m}^{2}\right)$ & & & $29.7 \pm 5.3$ & & & $27.4 \pm 4.4$ & 0.093 \\
\hline Arthralgia & 13 & 34.2 & & - & - & & \\
\hline Paresthesia & 11 & 28.9 & & - & - & & \\
\hline Growth hormone (ng/mL) & & & $3.1 \pm 4.8$ & & & - & \\
\hline Insulin-like growth factor-1 $(\mathrm{ng} / \mathrm{mL})$ & & & $426.7 \pm 371.4$ & & & - & \\
\hline Medical treatment $\mathrm{n}(\%)$ & 22 & 57.9 & & - & - & & \\
\hline Disease duration (month) & & & $75.6 \pm 79.5$ & & & - & \\
\hline Treatment duration (month) & & & $17.1 \pm 25.0$ & & & - & \\
\hline
\end{tabular}




\begin{tabular}{|c|c|c|c|}
\hline & Acromegaly group $(n=38)$ & Control group $(\mathrm{n}=21)$ & \\
\hline & Mean \pm SD & Mean \pm SD & $p^{*}$ \\
\hline Right median $\left(\mathrm{mm}^{2}\right)$ & $18.0 \pm 4.1$ & $11.9 \pm 3.3$ & $<0.001$ \\
\hline Right flexor pollicis longus $\left(\mathrm{mm}^{2}\right)$ & $16.5 \pm 3.9$ & $12.7 \pm 2.9$ & $<0.001$ \\
\hline Right elbow (mm) & $1.7 \pm 0.4$ & $1.1 \pm 0.5$ & $<0.001$ \\
\hline Right Achilles tendon $\left(\mathrm{mm}^{2}\right)$ & $63.5 \pm 13.1$ & $51.4 \pm 9.0$ & $<0.001$ \\
\hline Left median $\left(\mathrm{mm}^{2}\right)$ & $17.5 \pm 3.6$ & $12.5 \pm 4.0$ & $<0.001$ \\
\hline Left flexor pollicis longus $\left(\mathrm{mm}^{2}\right)$ & $15.7 \pm 3.5$ & $12.3 \pm 2.9$ & $<0.001$ \\
\hline Left elbow (mm) & $1.7 \pm 0.3$ & $1.0 \pm 0.6$ & $<0.001$ \\
\hline Left Achilles tendon $\left(\mathrm{mm}^{2}\right)$ & $63.6 \pm 13.0$ & $51.4 \pm 10.1$ & $<0.001$ \\
\hline
\end{tabular}

Table 3. Comparison of soft tissue measurements by disease activity state

\begin{tabular}{|c|c|c|c|}
\hline & \multirow{2}{*}{$\frac{\text { Active }(\mathrm{n}=22)}{\text { Mean } \pm \mathrm{SD}}$} & \multirow{2}{*}{$\frac{\text { Inactive }(\mathrm{n}=16)}{\text { Mean } \pm \mathrm{SD}}$} & \multirow[b]{2}{*}{$p^{*}$} \\
\hline & & & \\
\hline Right median $\left(\mathrm{mm}^{2}\right)$ & $18.9 \pm 4.4$ & $15.8 \pm 2.4$ & 0.012 \\
\hline Right flexor pollicis longus $\left(\mathrm{mm}^{2}\right)$ & $16.8 \pm 4.0$ & $16.2 \pm 3.9$ & 0.665 \\
\hline Right elbow (mm) & $1.73 \pm 0.4$ & $1.83 \pm 0.4$ & 0.506 \\
\hline Right Achilles tendon $\left(\mathrm{mm}^{2}\right)$ & $62.5 \pm 12.4$ & $64.8 \pm 14.4$ & 0.623 \\
\hline Left median $\left(\mathrm{mm}^{2}\right)$ & $18.1 \pm 3.6$ & $15.7 \pm 2.3$ & 0.024 \\
\hline Left flexor pollicis longus $\left(\mathrm{mm}^{2}\right)$ & $15.8 \pm 3.6$ & $15.5 \pm 3.7$ & 0.807 \\
\hline Left elbow (mm) & $1.75 \pm 0.4$ & $1.79 \pm 0.3$ & 0.791 \\
\hline Left Achilles tendon $\left(\mathrm{mm}^{2}\right)$ & $63.0 \pm 13.1$ & $64.5 \pm 13.1$ & 0.747 \\
\hline
\end{tabular}

great majority of subjects with acromegaly; actually, they may even be the earliest findings of these patients. ${ }^{11,16,17}$ Arthralgia is seen in $70 \%$ of patients in the early period and frequently takes the form of large joint involvement. ${ }^{2,8}$ In our study, arthralgia was present in 13 patients (34.2\%).

In a recent study, Karkucak et al. ${ }^{12}$ showed that femoral cartilage thickness, which is load bearing, is significantly greater in acromegaly patients but that this thickening was not associated with disease characteristics. Coalo et al. ${ }^{10}$ used US to monitor 18 acromegaly patients who were given octreotide therapy for six months. At the beginning of treatment, they determined greater knee, shoulder and wrist cartilage thickness and Achilles tendon diameter in active acromegaly patients compared to the healthy controls. They observed a significant decrease in cartilage thickness at the end of therapy and they emphasized that US was a convenient imaging technique in that regard..$^{10}$ In another study, they have again used US first to examine joint cartilage in 12 untreated active acromegaly patients. ${ }^{11}$ They determined that shoulder, knee and wrist cartilage thicknesses were approximately twice as high in active patients (more predominant in active patients). Thereafter, they also monitored acromegaly patients for 12 months with octreotide therapy. They observed decreased cartilage thickness in both load bearing (knee) and non-load bearing (shoulder and wrist) joints. However, the change in non-load bearing joints was statistically more significant when compared to that of load bearing joints. The aforementioned findings also correlated with the clinical parameters and IGF-1 levels. ${ }^{11}$ In the current study, we used the elbow joint (which is less prone to trauma than the non-load bearing shoulder and wrist joints) and observed higher humeral cartilage thickness in patients compared to the healthy controls.

Symptomatic carpal tunnel syndrome is a common condition in acromegaly, with a prevalence ranging from $20-52 \%$ up to $64 \%$ of patients at disease onset. Nerve conduction studies have documented subclinical abnormalities in the vast majority of patients. ${ }^{5}$ In one magnetic resonance imaging study, Jenkins et al. ${ }^{18}$ showed that acromegaly patients with symptoms of neuropathy had greater nerve size and signal intensity when compared to asymptomatic patients. However, volume of carpal tunnel contents in patients showing symptoms of carpal 
tunnel syndrome was not different from that of asymptomatic patients. ${ }^{18}$ The predominant pathology of median neuropathy in acromegaly consists of increased edema of the median nerve rather than extrinsic compression due to nearby soft tissues in the carpal tunnel. Similarly, Tagliafico et al. ${ }^{19}$ determined significantly increased median and ulnar nerve volumes in acromegaly patients by using US. They suggested that peripheral nerve enlargement in acromegaly seems to be an intrinsic feature of the disease related to clinical control, disease duration and IGF-I levels. ${ }^{19}$ Median nerve CSA values (but not cartilage/tendon measurements) were greater in our active patients as compared to inactives (not correlated with $\mathrm{GH}$ and IGH-I levels though). This difference might be associated with the structural characteristics (elasticity) of the nerve tissue.

Resmini et al. ${ }^{20}$ sonographically investigated median nerve diameters in the forearm of acromegaly patients. Although the decrease in forearm nerve diameters at one-year follow-up was statistically significant, this was not significant at the wrist level. They emphasized that flexor tenosynovitis or carpal tunnel syndrome at the wrist level may affect this change. ${ }^{20}$

Laboratory parameters are used as cure criteria in the treatment of acromegaly. A GH level below $1 \mathrm{ug} / \mathrm{L}$ and serum IGF-1 level within normal limits according to age range after oral glucose loading is accepted as cure. There are also studies showing that acromegaly activity can persist even at values below these levels. ${ }^{21}$ However, no gold standard imaging to identify possible soft tissues changes during the disease course has been established.

Lack of further studies on this subject for over about a decade after the above mentioned studies was a reason that led us to re-examine the topic, and highlight the availability and ease of use of this method for detection of soft tissue changes in acromegaly.

In conclusion, US is a practical and feasible method to show various articular and soft tissue pathologies. Changes of musculoskeletal systems, flexor pollicis longus and Achilles tendon respectively in acromegaly patients were shown by means of US in addition to nerve and cartilage examination. Median nerve CSA values were greater in active patients compared to inactive patients. Soft tissue changes can be described ultrasonographically in acromegaly. Additional wide-ranging, prospective studies are needed for determining musculoskeletal changes following a stealthy course in disease activation and for the development of guidelines.

\section{Declaration of conflicting interests}

The authors declared no conflicts of interest with respect to the authorship and/or publication of this article.

\section{Funding}

The authors received no financial support for the research and/or authorship of this article.

\section{REFERENCES}

1. Bauman G, Growth hormone and its disorders. In: Becker KL, editor. Principles and Practices of Endocrinology and Metabolism. 3rd ed. New York: Lipincott Williams \& Wilkins; 2001. p. 129-45.

2. Podgorski M, Robinson B, Weissberger A, Stiel J, Wang S, Brooks PM. Articular manifestations of acromegaly. Aust N Z J Med 1988;18:28-35.

3. Roelfsema F, van Dulken H, Frölich M. Long-term results of transsphenoidal pituitary microsurgery in 60 acromegalic patients. Clin Endocrinol (Oxf) 1985;23:555-65.

4. Lacks S, Jacobs RP. Acromegalic arthropathy: a reversible rheumatic disease. $\mathrm{J}$ Rheumatol 1986;13:634-6.

5. Baum H, Lüdecke DK, Herrmann HD. Carpal tunnel syndrome and acromegaly. Acta Neurochir (Wien) 1986;83:54-5.

6. Lieberman SA, Hoffman AR. Sequelae to acromegaly: reversibility with treatment of the primary disease. Horm Metab Res 1990;22:313-8.

7. Ozçakar L, Tok F, De Muynck M, Vanderstraeten G. Musculoskeletal ultrasonography in physical and rehabilitation medicine. J Rehabil Med 2012;44:310-8.

8. Ucuncu F, Capkin E, Karkucak M, Ozden G, Cakirbay $\mathrm{H}$, Tosun $\mathrm{M}$, et al. A comparison of the effectiveness of landmark-guided injections and ultrasonography guided injections for shoulder pain. Clin J Pain 2009;25:786-9.

9. Batmaz I, Kara M, Tiftik T, Capkin E, Karkucak M, Serdar OF, et al. Ultrasonographic Evaluation of the Femoral Cartilage Thickness in Patients With Ankylosing Spondylitis. West Indian Med J 2014;63:333-6.

10. Colao A, Marzullo P, Vallone G, Marinò V, Annecchino $\mathrm{M}$, Ferone $\mathrm{D}$, et al. Reversibility of joint thickening in acromegalic patients: an ultrasonography study. J Clin Endocrinol Metab 1998;83:2121-5. 
11. Colao A, Marzullo P, Vallone G, Giaccio A, Ferone $\mathrm{D}$, Rossi $\mathrm{E}$, et al. Ultrasonographic evidence of joint thickening reversibility in acromegalic patients treated with lanreotide for 12 months. Clin Endocrinol (Oxf) 1999;51:611-8.

12. Karkucak M, Batmaz İ, Civan N, Kilinc F, Capkin E, Sariyildiz MA, et al. Ultrasonographic measurement of femoral cartilage thickness in acromegalic patients. Clin Rheumatol 2015;34:157-61.

13. Giustina A, Barkan A, Casanueva FF, Cavagnini F, Frohman L, Ho K, et al. Criteria for cure of acromegaly: a consensus statement. J Clin Endocrinol Metab 2000;85:526-9.

14. Giustina A, Chanson P, Bronstein MD, Klibanski A, Lamberts S, Casanueva FF, et al. A consensus on criteria for cure of acromegaly. J Clin Endocrinol Metab 2010;95:3141-8.

15. Elmlinger MW, Kühnel W, Weber MM, Ranke MB. Reference ranges for two automated chemiluminescent assays for serum insulin-like growth factor I (IGF-I) and IGF-binding protein 3 (IGFBP-3). Clin Chem Lab Med
2004;42:654-64.

16. Colao A, Ferone D, Marzullo P, Lombardi G. Systemic complications of acromegaly: epidemiology, pathogenesis, and management. Endocr Rev 2004;25:102-52.

17. Barkan A. Acromegalic arthropathy and sleep apnea. J Endocrinol 1997;155:41-4.

18. Jenkins PJ, Sohaib SA, Akker S, Phillips RR, Spillane K, Wass JA, et al. Ann Intern Med 2000;133:197-201.

19. Tagliafico A, Resmini E, Nizzo R, Bianchi F, Minuto F, Ferone D, et al. Ultrasound measurement of median and ulnar nerve cross-sectional area in acromegaly. $\mathrm{J}$ Clin Endocrinol Metab 2008;93:905-9.

20. Resmini E, Tagliafico A, Nizzo R, Bianchi F, Minuto F, Derchi L, et al. Ultrasound of peripheral nerves in acromegaly: changes at 1-year follow-up. Clin Endocrinol (Oxf) 2009;71:220-5.

21. Melmed S, Casanueva F, Cavagnini F, Chanson P, Frohman LA, Gaillard R, et al. Consensus statement: medical management of acromegaly. Eur J Endocrinol 2005;153:737-40. 